\title{
The Roles of Universities in Development
}

\subsection{Introduction}

Since the last decades of the twentieth century, most countries, including the Kingdom of Saudi Arabia, have been seeking to transform their economies from depending on primary natural resources to a knowledge-based one, providing a permanent source for economic growth, and thus achieving sustainable development, and helping in diversifying the national economic framework, and multiplying income and wealth resources of the country other than primary resources, mainly crude oil.

In all countries of the world, sustainable economic development is facing challenges imposed by modern developments caused by globalization and fierce competition. Consequently, economic development now is in need for creativity and innovation, rising competitiveness for advanced industries, increasing its efficiency, and managing investment risks, in addition to its need for high-skilled human resources inputs. This is where universities' role comes into action as a basic resource with their human assets and research institutions capable of producing knowledge, creativity, and innovation represented in researchers, research centers, and scientific departments. Universities are considered a resource of economic development and the most important inputs of production processes for the knowledge-based economy in this century. Pioneering universities represent an integral part of the production system of innovations and technologies and its transferring to business and society [1].

As known, this is the age of information and knowledge, and this is due to the reliance on scientific research, creativity, and innovation. Also, the foundations of today are laid upon the achievements of the industrial revolution followed by information and communication revolution.

Information and communication revolution, supported by increased efforts and achievements of scientific research, lead to multiplied and varied knowledge of science and technology. Furthermore, the global openness and substantial development in the means of mobility and communication showed that the reached innovations, achievements, and inventions are not the end but still to be transformed and translated into the industrial practical field, achieving record profits and returns. This caused the transformation into economics of knowledge as a natural outcome of the effective transformation to knowledge societies in many countries.

Every country is keen on exploring natural resources and developing its means and capabilities. Recent studies show that the richest untapped resources in the Arab region, especially within the last two centuries, would be the power of the human mind. Although major industrialized countries have far preceded us toward technology renaissance since more than a century, the modern thinking renaissance march has not started until the late decades of the twentieth century, thus giving hope in catching up, provided that an initiative should be taken to embark into this field with the needed persistence, vision, and strategy.

Thinking is the main function distinguishing man than other creatures. It is a valuable and continuous mental process for achieving a certain goal, may be represented in a solution for a problem, or generating an effective idea to reach the main goal which is moving to a better condition.

One who studies or considers world countries would find out that most points of comparison center around what is called: Developed and developing countries; rich and poor countries; first-world and third-world countries. Some researchers focus on certain criteria, such as individual income level, availability of resources, industry, and technical development. These criteria actually represent a part of the needed requirements for transforming communities or countries from poor into rich countries, or from developing into advanced countries on the right path. The key is the countries' ability to narrow the knowledge gap, without which third-world countries or countries aiming at transformation into communities and economies of knowledge would be unable to transcend to the level of developed countries [1]. 
Accordingly, narrowing or filling the knowledge gap is the doorstep to moving from regress to progress, whether it is economic, scientific, or cultural regress in general. It should be taken into consideration that nations' wealth is no longer centered on natural material and sources of wealth such as natural resources and lands, and it is rather represented in knowledge. That explains how countries that lack natural resources, such as Japan, Switzerland, Denmark, and Singapore, turned wealthy because of their knowledge resources. Such countries have become among the world's richest and highest GDP per capita countries. Meanwhile, some of the richest countries in terms of natural resources, such as Russia and Brazil, are of low GDP per capita income in comparison with other major countries [1].

Albeit thinking is individual at first place, its role gets more important in different institutions and countries on an individual, collective, or institutional scale, where thinking becomes a vital element adding to value, which leads to achieving excellence and superiority, and promotes leadership and competitiveness. Knowledge and thinking are the main tools for creativity for their contribution to continuous development of institutions and countries. Knowledge is an intellectual capital representing the thought and action outputs of selected operatives endowed with knowledge and organizational abilities to produce and develop new ideas, and learn continuously how to improve their institutions for optimizing their competitive capabilities. Effective institutions, and even countries that follow progress path primarily in the age of knowledge, are based upon the effort, creations, and innovations of human resources and intellectual capital.

\subsection{Creativity and Innovation}

Creativity has many definitions such as the ability to produce a work that is of two qualities: be unprecedented and adequate [2]; or it is the ability to see potential things that are not realized by others [3]. It is also defined as a sensitive and critical process that results in the generation of new ideas [4].

As for innovation, it may be perceived as applying a new product or an innovatively developed product, whether it is a commodity, a service, an application of production processes, new methods of marketing, or modern organizational methods. On another hand, innovation is defined as intended incorporation and application of creative ideas in a business, or a system of businesses, including processes, products, and new procedures in business leading to creating something of value that may be accepted and marketed in society. Innovation can be also perceived as new ideas produced and promoted in markets for the first time, ensuring that something new is presented at the market [5].

\subsection{Relationship Between Creativity and Innovation}

From the definitions provided, we can see the overlap between creativity and innovation, but it is safe to say that creativity is a permanent resource for innovation, while innovation is an application and implementation of creativity; thus, creativity and innovation are inseparably related, which reflects their complementarity in providing what is new and adding value.

There are many theories about creativity and innovation, but here, we highlight the concerned theory in terms of universities' role in building the economy of knowledge, which mainly focuses on creativity and innovation. This is because creativity gives no space for innovation unless it finds its way to application and marketing. A creative idea is nothing more than a realization or a vision; then, it is transferred into a product and becomes an innovation.

The end-product theory (or approach) tackles this interrelationship. The theory refers to the interrelationship between creativity and innovation, where the chain starts with creativity as a new applicable idea and then ends in the form of a product, a business, or some output. The creative experiment is the opposite of the reproduction experiment [6].

\subsection{Importance of Knowledge for Creativity and Innovation}

Scientific research, basic theoretical or practical studies, is extremely important in achieving the utmost benefit from scientific knowledge in innovation and development. Knowledge has become the focus of attention of countries that realized its importance in achieving sustainable development and global companies seeking to maintain the stature of their product around the world, in addition to scientific institutions (universities and research centers).

Development processes in developed countries have become to revolve around the concept of knowledge-based economy, as it leads to creativity and innovation. A society with knowledge is one that is capable of dealing, interacting, contributing, participating, producing, creating, and innovating.

The importance and role of knowledge in creativity and innovation can be summarized in the following points [7]:

1. Using and employing knowledge in fields of business and services; commodity production; and all economic activities, 
2. Scientific and practical knowledge is the key basis for achieving innovations, discoveries, and technological inventions,

3. Continuous increase in investments directly related to knowledge, which results in forming knowledge capital represented by Intangible assets,

4. Continuous increase in institutions and projects working in terms of producing and using knowledge, represented by information, communication and software companies, and research and advisory institutions,

5. Preparing opportunities for institutions to focus on the most innovative departments and to encourage individuals of these departments to be continuously creative and innovative.

\subsection{Creativity and Innovation in Universities}

Universities have become the source of power in the knowledge-based economy of the century, as they represent an integral part of the production chain of innovations and skills and transferring them to business and society.

Many universities have a lot of programs, curricula, workshops, and mechanisms that have been developed to encourage students on creativity and innovation and improve their cognitive functions. Cropley et al. consider that most creativity mechanisms and programs, such as brainstorming and other mechanisms and methods of producing creative ideas, address only one side of creativity sources [8].

Consequently, innovation is a main factor that plays an important role in universities' tasks and is represented in using and employing the activities and outputs of universities' mission in education and scientific research fields, employing them in community service and thus achieving revenue for universities. As for knowledge triangle, including education, scientific research, and innovation, we denote that innovation is the resultant of education and scientific research through creative knowledge and reaching new ideas, business, and products, or developing and improving what is already there, transferring knowledge beyond universities, participating with business and society, and applying achieved innovations and transferring them to commodities and services. At the end of the twentieth century, world universities in developed countries started offering study programs for creativity, innovation, and entrepreneurship and focusing on applied researches solving business problems in addition to paying attention to knowledge transfer and exchanging activities between universities and business institutions. Furthermore, they focused on intermediary technology institutions, technology centers, technology transfer firms, business incubators, start-ups establishing projects for industrial investment of knowledge and the development of knowledge transfer partnership. This aimed at developing and achieving a business income from the outputs of the scientific research activities and marketing them in business sector to compensate the decline in public funds for universities.

Governments of these countries encouraged such role out of urging universities to transfer and transform the outcomes of science, technology, creativity, and innovation to the service of economy. As a means of supporting universities role in creativity and innovation and building a knowledge-based economy, governments established a new type of organizational structures for boosting creativity and innovation processes and their transfer from universities to business institutions, and developing what is known as knowledge mediators and knowledge brokerage, represented in institutions whose job is to facilitate knowledge transfer, use, and sharing between universities and business sector through a two-way process. One way is having a university more open to community and the world, while the other is building a strong relationship between community and university, where they work on providing expertise, marketing knowledge, increasing academics, and executives focus on mutual interests, publishing, and implementing innovations for achieving their main objective, which is supporting and developing business, thus achieving economic prosperity through utilizing the university's capabilities for providing high-efficiency skills and high-quality basic, practical researches and for spreading the research and innovation culture.

The true value of any institution, including universities, lies in creative capital or intellectual human capital which means the mental capability for generating new adequate ideas with high quality. Creative intellectuals would be capable of employing their ideas by transforming them into valuable products and services achieving leadership, securing profits and good competitive position for their institution. Creative capital or intellectual human capital is one of the most important resources through which institutions can be competitive, representing the origin and basic resource for knowledge [9]. This capital, as a basic source for creativity and innovation, represents a strategic resource with high knowledge, mental energy, and distinguished skills and capabilities.

Universities are the institutions that embrace intellectual human capital the most. They serve as knowledge institutions that comprise teaching staff, researchers, and students, thus being a huge stock of skills and potentials that can bring constantly growing returns of creativity, generation of ideas, and innovation in an organizational environment and culture. The objective of universities' executive administration is centered on the proper management and utilization of the intellectual human capital. This represents a challenge for the university administration, but the greatest challenge yet 
is to transform ideas into intellectual or material values for work, production, and life; in other words, into knowledge in general. This indicates the transformation from thinking and creativity into innovation; it also suggests the transformation from creative university stage into innovative productive university stage. Management of intellectual human capital has become a top priority for universities for achieving many goals, such as creativity, social research production, applied scientific research publishing and marketing, and bringing about welfare to their communities [10].

Innovative universities represent an essential basis for delivering and exchanging knowledge, information, and human resources industry, making them either a strength or a weak factor of communities. Therefore, a university can be defined as the "engine of progress, beacon of enlightenment and forward-looking intellectual pillar." At the same time, it is a factory for preparing, forming, and qualifying successive generations and an entity entrusted with solving community problems through practicing them, creatively interact with them and objectively understand their dimensions [11]. Universities have to activate participation, transfer and exchange of information, and transform such information in individuals' minds to achieve required competitiveness; in order to be based on learning and knowledge generation; or obtaining, transferring, or utilizing information to reach new knowledge for solving their problems; or commercially investing it in cooperation with other different sectors of community.

Universities emerged as primary drivers in economics of knowledge, and they are expected to play vital roles in innovation and technology development. While a leading research university has become a key requirement and an important asset for economy, it is insufficient in itself for creating strong regional economic growth due to universities' tendency toward being catalysts for technology innovation, more than being drivers. Hence, universities must make use of their various strength points in boosting creativity and innovation processes and play more roles and exert further efforts in developing products and generating start-ups for applying achieved innovations, increasing graduate employment and effectively contributing in increasing their financial resources, thus contributing in economic development for community, as shown in Fig. 1.1.

\subsection{The Role of Innovation in Development}

Knowledge economy is based on knowledge and innovation and their consequent advanced techniques and regulations granting national economy high capacities of competitiveness and sustainability. Thus, tackling the indicators of knowledge economy at a national economy scale or at a partial scale, as in universities, requires identifying the components of knowledge economy and innovation in particular.

Innovation, previously mentioned, is a process of developing and improving the existing products or creating brand-new ones, in addition to enhancing processes and ways of production, services, business, or organizational models. In this sense, innovation is the basis for the knowledge-based economy and the main driver of the process of economic growth.

Innovative activities can be divided into four types: product-associated activities (technical in nature); activities associated with trademarks and distribution channels, with a product-delivery nature; activities associated with knowledge use or customer relationship management system, related to internal processes of organizational and institutional facilities; and activities associated with business models.

We can conclude that innovation has several forms including new products (goods and services), production processes, business practices, organizational and business models. And there are innovations directed at achieving social gains, known as "social innovations."

Economists are convinced day after another of the importance of innovations' role in the process of economic growth at the expense of capital accumulation in the long term. According to The Organization for Economic Co-operation and Development "OECD," the motive for increased economic development and high standard of living following the Second World War is represented in the rapid progress in technology and innovation. It is also estimated by USA commercial service that more than $75 \%$ of USA economic growth was driven by technological innovations since the Second World War until recently. A study on 98 developed and developing countries showed that around $90 \%$ of the real growth of average income per capita is attributable to innovation [12].

Fig. 1.1 Processes of knowledge at the university
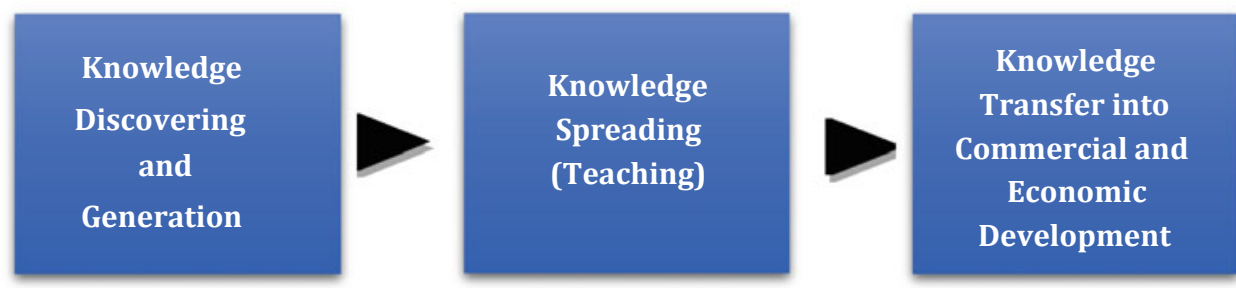
Innovation leads to economic growth through providing institutions with new competitive advantages, raising productivity of traditional elements of production, opening broader areas for new investments and advanced products, increasing employment opportunities, rising wages by promoting productivity, and leading growth, employment, and wage rise toward prosperity.

In light of the local and global challenges faced by economy in the twenty-first century, countries have been calling for working hard on increasing competitiveness for their economy by focusing on knowledge as a main element in development. As for the Arab world, including Saudi Arabia, the Kingdom's Ninth Development Plan spotlighted the importance of increasing expenditures on scientific research up to the global levels to achieve development goals which are possible in case of having an innovation and knowledge-based economy where institutions, especially universities, should play a vital role in increasing their outcomes of knowledge, innovations, and technology development at the same global levels.

In order to perform their role, universities have to break out of the box of traditional ways and methods of teaching and scientific research which limit knowledge output and start focusing on creativity and innovation processes, utilizing modern techniques to improve the quality and quantity of the process of knowledge generation, production and spreading in a way that serves practical life and development progress for communities [13]. They are also required to provide a clear-objective mission at every level; pushing their members toward teamwork commitment; avoiding individualism; evaluating the effectiveness of educational process and university outputs; in addition to continuous interaction with business sectors for community development and enhancing mutual interest; and direct effective contribution in serving community, solving its problems, and fulfilling its recurring needs, as well as contributing to community development and knowledge increase.

\subsection{Innovation in Saudi Arabia' Economy}

Being important for world economies, innovations have also a special importance for Saudi economy that has been based on utilizing oil as a natural resource of income and wealth in community for many years since the discovery of oil until now. Hence, the Saudi economy's need for building a diverse economic base focused on high-technology activities has become an urgent priority for diversifying income and wealth resources, driving economic growth, and providing high-productivity and high-income job opportunities.

Hence, it is important to establish partnership between universities and business sectors in the Kingdom, as the challenge today is the establishment of an economy based on modern technology and knowledge, then establishing projects in different economic fields, especially modern manufacturing, that depend on modern inputs, innovations, and technology, or knowledge-acquainted or highly skilled human resources. Innovation and modern technologies not only provide new products, but also establish new industries, which in turn increase added value, diversifying economy, creating new high-productivity and high-income job opportunities, and increasing competitiveness for local industries.

Technology support institutions have many advantages relating to spreading knowledge and promoting investment in national economy. At the beginning of the current decade (2011-2020), business incubators in North America provided job opportunities for eight thousand people, and an annual income of more than 7 billion US dollars, while in Europe, business incubators created about forty thousand job opportunities annually [14].

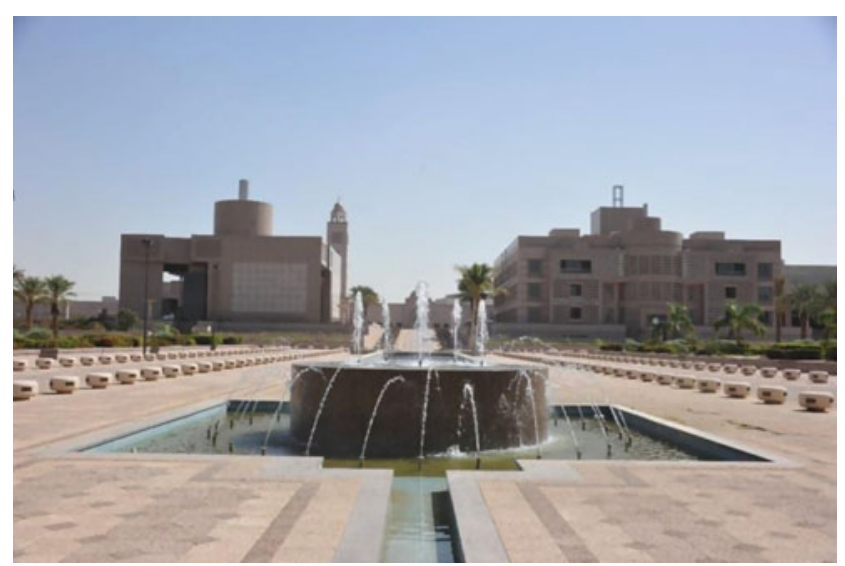

King Abdulaziz University, a pioneering university in KSA

Given the aforementioned, the government of the Custodian of the Two Holy Mosques has been seeking to achieve comprehensive development that would put the country on the list of developed countries by bringing about a broad knowledge leap and building three complimentary pillars: strong economy not based on complementary oil. Therefore, the Kingdom issued Vision 2030 [15]: A vibrant society, a thriving economy, and an ambitious nation. These pillars are coherent for achieving the objectives and maximizing the use of the vision's pillars. For community is where the vision starts and ends. The first pillar, emerging from faith in building up a community, represents the base of achieving this vision and establishing a solid foundation for the prosperity of the Kingdom's economy. In its second pillar (a thriving economy), the vision focuses on providing 
job opportunities for all by building an educational system related to labor market needs and developing opportunities for all, starting from entrepreneurs and small-scale enterprises to large companies. It also stresses developing the Kingdom's investment tools to unleash the potential of the promising economic sectors, diversify economy, generate job opportunities for citizens, and revitalize competitiveness leading to raising the quality of services and economic development, whereas efforts are focused on privatizing government services and enhancing business environment which contributes to attracting the best global competencies and specific investments in addition to utilizing the Kingdom's unique strategic location. The vision's third pillar concentrates on public sector, where it outlines the active government through enhancing efficiency, transparency, and accountability; encouraging culture of performance to empower human energy and resources; and preparing the environment required for citizens and business and non-profit sectors to take their responsibilities; in addition to taking the initiative in face of challenges and seizing opportunities.

Saudi Arabia's Vision 2030 targeted many objectives, including education and its consequent economic growth, such as:

1. Enabling five Saudi universities at least to be among the world's top (200) universities by 2030 ,

2. Providing educational opportunities for all in a suitable environment in light of the educational policy of the Kingdom,

3. Raising the quality of educational outputs,

4. Increasing the effectiveness of scientific research,

5. Encouraging creativity and innovation,

6. Developing community partnership.

\subsection{Experiments of Pioneering Innovative Universities}

Here, we briefly present some successful experiments of world's pioneering universities in terms of creativity and innovation. Developed countries around the world managed to maintain the momentum toward further development and economic progress through building innovative capacities and advanced technology, and forming communication and linking networks between innovation system stakeholders represented in universities, research centers, business sector, and government that helped in building an environment capable of transforming ideas into successful outputs, enabling them of producing new commodities and services and creative economic values. These experiments include:

\subsubsection{Massachusetts State Universities in USA}

USA state of Massachusetts has nine research universities; on top of them are Massachusetts Institute of Technology (MIT) and Harvard University [16], which are placed among top three universities in the world, in addition to other seven research universities listed among the world's top 100 universities [17-19]. In their local and national community, these universities push economic growth through their impact upon the state of Massachusetts because of their various contributions to developing the region in many technological fields.

This impact is represented in the following:

1. Obtaining patents granted by world offices,

2. Granting licenses annually for establishing new companies that would impact economic growth process,

3. Providing services and facilitation to educate senior graduates and workers and train them to acquire skills to do advanced jobs,

4. Providing offices and laboratories to support the expertise of new businesses, encouraging them to grow.

Historically, Massachusetts is considered a center for entrepreneurship and innovation. Its research universities contributed to establishing many large companies, which are considered important partners for the university, such as Baojun. It also participated, in cooperation with its partners, in establishing hundreds of companies in the areas surrounding the universities. In 2000 particularly, universities helped in establishing 41 companies for business investment of technologies produced at these universities. They also granted 280 licenses for special projects in 2000, where universities received $\$ 44.5$ million. In addition, they also succeeded in attracting a number of global and national companies, to be settled in Boston (state capital), for developing basic and practical researches at the state.

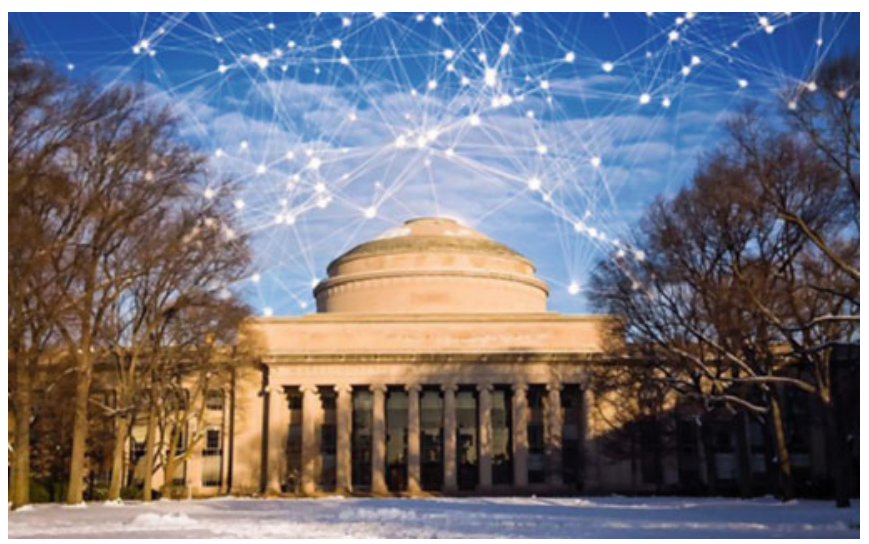

Massachusetts Institute of Technology (MIT) 


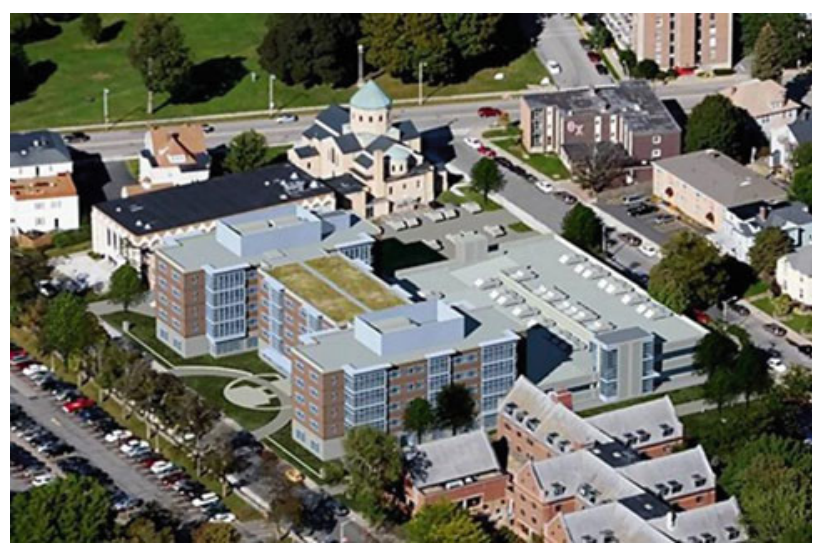

Boston University

\subsubsection{US Harvard University}

Harvard University provides its students with a broad platform for arts and science, as the university incurs huge costs for achieving such broad excellence, as its annual operational budget reaches $\$ 4$ billion [20]. Chapter 6 of this book includes more information about Harvard University.

\subsubsection{Science and Technology Parks}

Scientific research and innovation system is an important cornerstone for knowledge societies, as it comprises a group of units mainly established by the state, with the participation of the private sector at some of which. These units are research centers, science parks, and business incubators. Research centers are located next to scientific departments in most universities around the world, but science parks, in spite of their establishment long history in the USA and other developed countries, have no specific definition, yet include the following components:

1. A real-estate area dedicated for the park.

2. An organizational structure for implementing activities of technology transfer.

3. Partnerships between higher educational institutions, government and private sector.

Innovative universities pay attention for establishing start-ups or technology incubators and providing required facilitation, which turns some of their students, graduates, and teaching staff into business pioneers, while these start-ups work on employing graduates and applying innovations. Thus, science and technology parks have become effective tools in development through focusing on scientific research and innovation, providing required facilitation and services for innovation, helping foster and develop innovation and competitiveness in industry, and providing job opportunities for competent and distinguished individuals. In addition, they foster and help small and medium-sized enterprises (SMEs) in high-technology business fields. As a result, economy would be transformed from a naturalresource-based economy into innovation and technologybased one [21].

Innovation-based economy has become a powerful factor, pushing outstanding universities toward changing the policies of scientific research, as universities seek to direct their support to generate, encourage, and provide fund for creators and innovators. Thus, education and researches in universities are expected to be greatly impacted by knowledge-based industrial companies, whether established inside or outside universities [22]. In the USA and Japan, experiments proved that cooperation between teaching staff and industrialists plays an important role in the success of these companies, as researchers and academics participation in industrial researches and consultancies provided for industrial bodies are key factors for their success in the environment of knowledgebased economy.

\subsubsection{Start-Ups}

A start-up company is a newly established company in the first stage of its operations, development, and search for markets. Start-up founders effectively develop a scalable business model. Hence, the concepts of start-ups and entrepreneurship are similar. However, entrepreneurship refers to all new businesses, including self-employment and businesses that never intend to grow big, while start-ups refer to new businesses that intend to grow beyond the solo founder, have employees, and intend to grow large, but at the same time, only few companies go on to be successful, large, and influential. The simple launch of the start-up through self-funding or external funding with low initial capital makes it attractive for investors and founder entrepreneurs. In addition, a start-up is characterized by rapid growth, and in spite of the inherent high risk, it has high potential returns [23].

Start-ups depend on many funding sources, such as:

1. Self-funding,

2. Individual investors,

3. Venture capital companies.

Start-ups design a business model before their launch. This model is supposed to be unique because distinctiveness and excellence of ideas are the key factors of a start-up success and its most important means of achieving growth and expansion [24]. 
Open Access This chapter is licensed under the terms of the Creative Commons Attribution 4.0 International License (http://creative commons.org/licenses/by/4.0/), which permits use, sharing, adaptation, distribution and reproduction in any medium or format, as long as you give appropriate credit to the original author(s) and the source, provide a link to the Creative Commons license and indicate if changes were made.
The images or other third party material in this chapter are included in the chapter's Creative Commons license, unless indicated otherwise in a credit line to the material. If material is not included in the chapter's Creative Commons license and your intended use is not permitted by statutory regulation or exceeds the permitted use, you will need to obtain permission directly from the copyright holder. 